\title{
Importância do Conhecimento de Anatomia Humana para a Educação Física
}

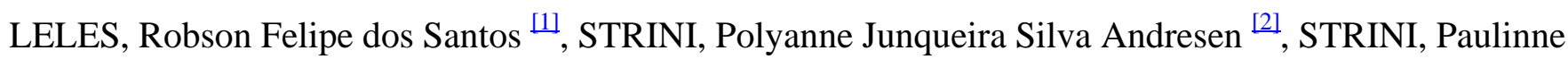
Junqueira Silva Andresen ${ }^{[3]}$, PUTRICK, Simone Cristina ${ }^{[4]}$, OLIVEIRA, Euzébio de ${ }^{[5]}$, DENDASCK, Carla Viana ${ }^{[6]}$

LELES, Robson Felipe Dos Santos; et.al. Importância do Conhecimento de Anatomia Humana para a Educação Física. Revista Científica Multidisciplinar Núcleo do Conhecimento. Ano 02, Ed. 12, Vol. 02, pp 21-40, Dezembro de 2017. ISSN:2448-0959

\section{RESUMO}

Ambas as áreas de Educação Física e Anatomia Humana abordam temáticas relacionadas ao estudo e funcionamento do corpo humano, com aspectos em comum demonstradas ao longo da história da humanidade. Desta forma, o objetivo do presente trabalho é o de avaliar a importância do conhecimento de anatomia humana para o curso de educação física. Para isso, foi realizada uma revisão descritiva da literatura, por meio de pesquisa nas bases eletrônicas de dados da Biblioteca Virtual em Saúde (BVS), Lilacs, Medline, Scielo, Cochrane, Pepsic, Pubmed e Google Acadêmico. A seleção de artigos científicos foi realizada nos últimos 10 anos, contemplando a produção científica entre 2006 e 2016, utilizando as terminologias cadastradas nos Descritores em Ciências da Saúde (DECS), pela busca avançada e cruzamento dos termos em português e inglês, como: "anatomia" ou "anatomia humana" and "educação física" e "anatomy" ou "human anatomy" and "physical education". Diante dos estudos apresentados, pode-se notar a importância do conhecimento de estruturas anatômicas do corpo humano para estudantes e profissionais da Educação Física. Portanto pode-se concluir que sua real importância encontra-se subestimada, necessitando de pesquisas adicionais capazes de elucidar seu papel fundamental na formação intelectual, técnica e prática dos graduados.

Palavras-Chave : Anatomia, Educação Física, Conhecimento.

\section{INTRODUÇÃO}

A Educação Física e a disciplina de Anatomia Humana possuem aspectos em comum no decorrer da história, e para introduzir alguns desses aspectos que fazem relação a essas duas áreas de conhecimento, 
serão utilizados acontecimentos da história da arte que datam parte de grandes eventos pertinentes ao assunto que ocorreram no decorrer dos anos.

Segundo Cardinot et al. (2014), a disciplina de anatomia humana além de ser de fundamental importância para os cursos de Educação Física e Fisioterapia pode ser também considerada como um pré-requisito para as disciplinas seguintes da graduação desses cursos.

Para Piazza e Reppold Filho (2011), há séculos que a anatomia humana vêem sendo tratada, iniciando-se pelos egípcios, seguido pelos mesopotâmios e passando por alguns artistas, como, Galeno, Leonardo da Vinci, Michelangelo e Andreas Versallius. A história da arte e da anatomia estão interligadas uma com a outra desde o período dos homens das cavernas até os dias atuais e, ao se datar alguns acontecimentos no decorrer da história da humanidade, é perceptível o quanto essa área de conhecimento se evoluiu. E partindo desses tais acontecimentos, a anatomia foi se constituindo e se integralizando em inúmeras áreas inclusive a da educação física.

Justificando o desenvolvimento dessa pesquisa, é notável que seja importante publicar mais pesquisas que relevem a importância da disciplina de anatomia humana para os cursos de educação física, pelo fato também de ser uma área muito carente de estudos dessa relação. Levando em consideração essa disciplina da Faculdade de Educação Física e Dança (FEFD) da Universidade Federal de Goiás (UFG), há um trabalho constante dos professores para que os alunos consigam obter os conhecimentos necessários para a sua formação. O mesmo é realizado no Instituto de Ciências Biológicas III (ICB III), lugar onde ocorrem as aulas das turmas de educação física na modalidade licenciatura. Pelo que é perceptível à anatomia é de grande relevância para a vida profissional, mas também é do interesse saber o quanto os graduandos se dedicam em querer aprender sobre esta vasta área de conhecimento para no futuro estarem aplicando aquilo que tiveram de aprendizagem.

Torna-se importante pontuar também a necessidade dos profissionais da área que estejam se graduando agora, em ter a ciência da importância de um maior aprofundamento sobre a Anatomia Humana, pois eles estão saindo das Universidades com os saberes limitados e superficiais. Assim, surge a exigência em ampliar e detalhar o conteúdo trabalhado nessa disciplina, bem como incentivar a participação e o interesse discente, estimulando os estudos e a manutenção do conhecimento, uma vez que o mesmo acompanha toda a vida de um professor de Educação Física, independente de sua área e local de atuação profissional. Vale ressaltar que aqueles formados há muito tempo também devem se atualizar acerca dos novos estudos e pesquisas.

O presente trabalho traça como objetivo geral avaliar a importância do conhecimento de anatomia humana para o curso de educação física. E como objetivos específicos à pesquisa aponta identificar a relevância da disciplina de Anatomia para o curso de educação física, analisar a importância do conhecimento do corpo humano para profissionais da área e revisar a literatura sobre os objetivos estabelecidos.

Desta forma, é também notório possuir um embasamento histórico visando entender a importância da anatomia ao longo do tempo e nos dias atuais. Neste sentido, a revisão de literatura traz a história da anatomia no mundo e no Brasil, as noções básicas da ciência anatômica e também os aspectos introdutórios da educação física no intuito de situar o leitor no contexto a ser retratado. 


\section{REVISÃO DE LITERATURA}

\subsection{HISTÓRIA DA ANATOMIA NO MUNDO E NO BRASIL}

Os conhecimentos sobre a anatomia são fundamentais para o profissional de educação física. Os saberes desta imensa área e campo de estudo propiciaram grandes eventos no decorrer da história da humanidade e podem ser descritos da seguinte maneira:

Segundo Lira e Alves (2009), a anatomia é expressa na história desde o homem das cavernas, sendo o período Paleolítico uma época na qual não havia ainda sido desenvolvido a escrita. Desse modo, o homem comunicava-se em uma linguagem que somente ele conseguia entender.

O homem era um grande observador dos animais e das belezas naturais. Por meio dessas observações conseguia expressar alguns conhecimentos sobre anatomia e o fazia com base na arte rupestre, que era um meio de comunicação e expressão artística feita por meio de pinturas nas rochas e paredes das cavernas (LIRA; ALVES, 2009).

No período Paleolítico o homem demonstrou o seu entendimento sobre a anatomia humana feminina através da estatueta da Vênus de Willendorf, representada através do exagero em todas as partes do corpo (LIRA; ALVES, 2009).

Transitando para outro período na história da humanidade chega-se ao Neolítico, onde as pinturas dos animais registradas nas rochas e paredes são substituídas por pinturas humanas, pelo fato de passarem a exercer representatividade também no universo. Nas ilustrações da anatomia do homem é notável "ele" como um ser universal e generalizado (LIRA; ALVES, 2009).

Na Mesopotâmia, o olho é a parte constituinte do corpo humano que se dialoga com o mundo, fato destacado nas pinturas. Em exceção ao busto que permanecia de forma frontal, a cabeça, as pernas e os pés encontravam-se de perfil. As esculturas que eram produzidas não continham muitos detalhes anatômicos, contudo essas demonstravam um corpo rígido (LIRA; ALVES, 2009).

No Egito, os faraós e os deuses tinham a sua força e o seu poder demonstrados por corpos desproporcionais esculpidos na época. Nesse período, o culto ao corpo morto era notável, pois era pensado que um corpo intacto se prevaleceria e assim a vida daria continuidade mesmo após a morte. Houve um grande aprofundamento por parte dos egípcios sobre anatomia e fisiologia tendo o conhecimento de ossos, juntas, músculos e tendões (LIRA; ALVES, 2009).

O Teocentrismo defendia ser Deus o centro do universo, porém na Grécia, segundo Lira e Alves (2009), prevalecia-se o Antropocentrismo sendo o Homem o centro, tendo isso como referência á arte, o corpo humano toma foco. A presença do divino era vista nos rostos das esculturas, possuindo elas expressões de tranquilidade. Como o corpo humano era foco na Grécia, as esculturas corporalmente expressavam uma musculatura tensa dando representatividade ao ser humano.

O interesse do estado em Roma baseava-se em sua arte que era caracterizada como sendo utilitária e para a representação do poder de forma realista esculpiam-se rostos de autoridades. Para que os corpos fossem mitificados e divinizados em paredes de casas era utilizado da pintura mural (LIRA; ALVES, 2009). 
Na Idade Média, pelo fato de ter sido transfigurada, a anatomia do corpo passa a ser proibida. Nas pinturas, os corpos se apresentam alongados e com características como palidez tendo como base o sofrimento. Foi nessa época que a igreja decreta o impedimento de ter conhecimento sobre o corpo humano. Diante dessa situação a anatomia humana passa a fazer comparações com órgãos de animais (LIRA; ALVES, 2009).

De acordo com Lira e Alves (2009), o Renascimento é datado como sendo um período de grandes acontecimentos na história, pois a autonomia da ciência é recuperada, o corpo volta a ser objeto de produções de cunho artístico e o retrato surge como forma de expressão de identidade, e destaca-se a questão do artista cientista.

Leonardo da Vinci (1452-1519) foi o precursor principal do Renascimento e teve grande representação na área da anatomia humana por apresentar diversas funcionalidades de partes do corpo humano. Da Vinci estudou muito a respeito do corpo e do movimento trazendo grandes contribuições não somente para a anatomia, mas para todo o mundo diante de sua genialidade e descobertas (LIRA; ALVES, 2009).

Mantendo-se ainda no período do Renascimento nasce outro gênio do mundo artístico cujo nome é Miguel Ângelo di Lodovico Buonarroti Simoni (1475-1564), "Michelangelo", nascido na cidade de Capresse na Itália. Após ser descoberto e iniciar os seus estudos na Escola de Lorenzo de Médici em Florença onde poderia aflorar mais os seus conhecimentos, Michelangelo descobriu que a escola possuía grandes artistas italianos, contudo também se encontravam muitos médicos que foram quem despertaram o interesse pela anatomia através das sessões de dissecação (CORRÊA et al., 2008).

Como já mencionado, a dissecação foi proibida na idade média, portanto somente sob a autorização do Papa é que essa prática poderia ser realizada. Se fosse identificada de algum modo uma dissecação ilegal, a punição iria desde a prisão até a pena de morte (CORRÊA et al., 2008).

Michelangelo com 18 anos de idade já obtinha a sua formação artística e tinha grande conhecimento sobre anatomia e a utilizava em suas obras, contudo a sua vontade de querer cada vez mais aprofundamentos sobre essa área o fez fazer dissecações clandestinas com cadáveres de criminosos que eram executados, dentre outros (CORRÊA et al., 2008).

A dissecação em humanos iniciou-se no século XIV trazendo muitas contribuições para o entendimento sobre o próprio corpo humano, mas por questionamentos da igreja essa prática passou a ser proibida. Entretanto, com o decorrer dos tempos, percebeu-se a necessidade que as dissecações faziam e com isso era preciso que elas voltassem a ser legalizadas. Assim, no momento certo, a igreja revogou o que havia declarado antigamente e as práticas de dissecação voltaram à tona tendo as universidades como sendo as primeiras a realizarem tal feito (CORRÊA et al., 2008).

As dissecações voltaram a ser realizadas para se obter respostas sobre mortes consideradas como suspeitas. Em uma outra vertente, essa prática retorna por conta desse novo período que entra em ascensão sendo ele o renascimento, trazendo um novo olhar para o ser humano e também pelos novos ideais implantados (CORRÊA et al., 2008).

Com as grandes contribuições que estavam sendo colocadas na época, sobretudo por Michelangelo, que foi um grande precursor desse olhar para a anatomia humana, os artistas perceberam que para as suas 
obras chegarem à perfeição era preciso se adentrar nesse mundo anatômico. Apesar disso, o trabalho feito pelos os outros artistas não era o suficiente, pois era preciso analisar como o corpo humano é internamente. Desta maneira com o tempo artistas começaram a fazer e participar também de sessões de dissecação para trazer os aprendizados para as suas obras. Assim, é nessa época do Renascimento e principalmente de Michelangelo que nasce a anatomia moderna (CORRÊA et al., 2008).

O Barroco sendo uma tendência artística se instaurou em um período onde a religião passava por um processo de reformas, nas obras eram retratados corpos contorcidos com dramatização e teatralização (LIRA; ALVES, 2009). Logo no período Neoclássico retorna-se aos ideais promovidos pelo povo Grecoromano, onde o corpo é visto em uma figura realista tendo como contraste a palidez da pele em relação às esculturas clássicas (LIRA; ALVES, 2009).

Com conhecimentos sobre a anatomia os pintores eram os responsáveis diretos em representar a realidade em suas obras, mas com a chegada do modernismo há uma quebra no que já estava sendo imposto, assim as áreas cinematográfica e fotográfica passam a fazer essas capturas da realidade. Como o corpo não tem mais a necessidade de se apresentar-se como real, surgem movimentos, como: impressionismo, cubismo, surrealismo, entre outros para mostrarem um outro lado das composições corporais (LIRA; ALVES, 2009).

\subsection{NOÇÕES BÁSICAS DA ANATOMIA HUMANA}

Segundo Paulsen e Waschke (2012), “??????" (anatome) quer dizer “corte, fatia, secção”, e “????????? (anatemnein) significa "cortar, fatiar, seccionar". Então a anatomia sendo uma ciência, ela estuda o corpo por meio de cortes realizados pelos anatomistas. Quando as pessoas entendem alguns dos mistérios que o corpo humano esconde é iniciado um conhecimento sobre o todo.

Após os corpos mortos, os anatomistas podem realizar o seu trabalho. Contudo, diante do fato da anatomia se basear em pessoas mortas, na verdade se trabalha com a compreensão da vida, o que pode parecer confuso, mas a anatomia refere-se a isso em relação ao ser humano. Os cadáveres utilizados para os determinados estudos e trabalhos são colocados apenas como modelos (PAULSEN; WASCHKE, 2012).

De acordo com Costa, Costa e Lins (2012), apesar dos cadáveres serem peças de estudo para a disciplina de Anatomia Humana, é relevante colocar em questão que anteriormente existia toda uma relação emotiva e afetiva "desses" com as pessoas das quais se relacionavam. No entanto, essas questões fazem parte desse processo e da vida médica há muito tempo, pelo qual na medicina já ocorreram avanços positivos e a partir disso permitiu-se o trabalho ético com cadáveres.

Considerando o ser humano como uma máquina, e para que toda máquina tenha o seu devido funcionamento e desempenho esperados, logo se relacionam os elementos da seguinte maneira: a partir de um conjunto de células se originarão os tecidos, que assim irão se tornar órgãos. Portanto a união de todos esses concederão os sistemas, nos quais proporcionarão o funcionamento do corpo (EDUCAÇÃO FÍSICA, 2012).

Para o profissional de educação física em formação dentro da universidade, enquanto estiver cursando a disciplina de Anatomia do Movimento Humano, e como parte da ementa do curso é preciso ter 
conhecimento dos sistemas do corpo humano e para estudá-los existe um dos métodos de ensino de anatomia que abarca esse estudo denominado de anatomia sistêmica ou sistemática, que segundo Paulsen e Waschke (2012), é responsável por organizar e classificar. Esse método organiza o corpo em cada área de estudo.

Os sistemas do corpo humano são: Sistema Tegumentar, Sistema Esquelético, Sistema Muscular, Sistema Circulatório, Sistema Respiratório, Sistema Digestório, Sistema Urinário, Sistema Genital, Sistema Nervoso, Sistema Endócrino e Sistema Sensorial (EDUCAÇÃO FÍSICA, 2012).

Nos séculos XVII e XVIII, as dissecações eram realizadas a um público específico, essas eram feitas no tempo frio pelo fato de não se ter conhecimento de técnicas que conservassem os corpos que ali estavam sendo dissecados. Há o descobrimento do formol no século XIX, que até nos dias atuais é utilizado e está presente em vários laboratórios de Anatomia Humana. Desta maneira é utilizado pelo custo ser baixo e garantir uma penetração tecidual bem rápida, contudo produz um odor forte que chega há ser um pouco irritante (PIAZZA; CHASSOT, 2011).

Com o decorrer dos séculos XX e XXI, não houveram muitas descobertas com grande significação para a área de Anatomia Humana. Contudo os avanços que ocorreram enquanto técnicas de conservação dos cadáveres são enormes, algumas delas são a glicerinização e a plastinação inventada pelo médico alemão Gunther Von Hagens. Com essa técnica, existem peças anatômicas dele em exposição por todo o mundo (PIAZZA; CHASSOT, 2011).

Mantendo-se ainda nos séculos XX e XXI, tiveram outros avanços com bastante importância como à tecnologia e seus aparatos que facilitaram o ensino-aprendizagem tanto por parte dos professores como para os estudantes. Desse modo, os docentes passaram a ter um maior quantitativo de ferramentas para o ensino da anatomia e os discentes conjuntamente usufruíram cada vez mais dessas possibilidades de estarem aprendendo o conteúdo com uma maior facilidade (PIAZZA; CHASSOT, 2011).

Em alguns casos, professores que lecionam a disciplina de Anatomia Humana possuem uma formação escassa e ministram aula da mesma forma pela qual aprenderam na época de discentes, o que pode, de certa forma, ser ruim. Como ocorre e ocorreram muitas mudanças ao longo do tempo, o método pode não ser o mais adequado e/ou eficaz para a ocasião. Outros professores analisam primeiramente a situação na qual estão inseridas e qual será o público de suas aulas, e a partir daí, é passível deles escolherem qual seria o método que melhor se adequaria para o ensino da disciplina de anatomia humana (PIAZZA; CHASSOT, 2011).

Com o debate estabelecido no parágrafo anterior Cória-Sabini e Damasceno (2003) dizem que, os docentes ao lecionarem a disciplina de Anatomia Humana imaginam que a partir da teoria aplicada, os discentes imediatamente conseguirão se desenvolver na prática e nos aspectos técnicos para com a sua atuação acadêmica e/ou profissional, mas francamente não é isso que acontece. Para o desenvolvimento realmente se suceder por parte dos estudantes é preciso que as aulas sejam significativas, onde é possível que haja uma relação a partir do que é ensinado para o que é posto em prática.

Tardif (2002) expressa que, todo o conhecimento construído de um professor foi adquirido por causa de todo o processo pelo qual passou até chegar ao ponto de ser reconhecido pelos anos de trabalho. Entretanto, não se pode articular o ensino do professor com a aprendizagem do estudante, sem uma 
conversa e onde apenas uma das partes é que se responsabiliza por estar construindo o conhecimento. Assim, esta tarefa deve ser conjunta. O professor de Anatomia Humana deve adotar estratégias para aquilo que estiver transmitindo seja, de certa forma, compreendida pelos estudantes e a partir disso, os estudantes possam pegar esse conhecimento técnico, e desenvolvê-lo, se tornando também agentes de construção dos saberes.

\subsection{ASPECTOS INTRODUTÓRIOS DA EDUCAÇÃO FÍSICA}

A Educação Física é uma prática pedagógica do componente curricular da educação básica, que trabalha com os elementos da cultura corporal, como: Jogos, Esporte, Ginástica, Dança, Lutas (COLETIVO DE AUTORES, 1992).

O ser humano pratica atividades relacionadas ao corpo em todo o tempo, pois faz parte de sua essência essas atividades que se remetem ao movimento, com isso, foi construindo e fazendo a sua própria história. Assim sendo, esse se caracteriza com uma auto-expressão do homem. Na história, a concepção materialista-dialética diz que o homem utilizou-se do movimento para dar significado a sua vida e ao se fazer esse ato acabou não modificando somente a natureza, mas também a "natureza" dele mesmo. A partir disso, foi se constituindo cada vez mais e com a utilização de gestos, habilidades e movimentos foi garantindo desse modo a sua sobrevivência na natureza, criando algo cultural e significativo para a história da humanidade (MENESTRINA, 2005).

De acordo com Menestrina (2005), com tais características, viu-se que esses movimentos praticados pelo homem são os quais condicionam a sua relação com o seu meio, para assim poder se satisfazer e/ou para resolver os seus problemas. Dessa maneira a educação física se correlaciona com as questões das necessidades do homem e as suas movimentações, incorporando-se a prática cultural da sociedade, pelo fato de surgir como um movimento organizado pela humanidade.

O tempo foi demonstrando para a humanidade que a prática de atividades relacionadas com a saúde e o bem-estar físico deveriam estar reunidas ao seu cotidiano mais frequentemente, pois assim passariam a ser mais saudáveis demonstrando maiores cuidados com os seus próprios corpos (MENESTRINA, 2005).

Após os movimentos surgidos com o Modernismo, no Pós-modernismo o corpo se remete a padrões de estética com o propósito de ser lançado ao mundo por meio dos sistemas midiáticos. Desta maneira são dados novos parâmetros para a anatomia humana. O responsável por essa redefinição corporal é a tecnologia existente, no caso o computador constrói corpos perfeitos para a disseminação e consumo mundial, contudo esse corpo criado esteticamente e tecnologicamente é inatingível (LIRA; ALVES, 2009).

Conhecendo um pouco sobre a história da anatomia, observa-se a importância na formação de profissionais da área da saúde. Neste contexto, as disciplinas de Anatomia Humana e Neuroanatomia foram avaliadas no intuito de verificar se as mesmas atendiam as necessidades de disciplinas específicas do curso de Fisioterapia - FURB (Universidade Regional de Blumenau). Para isso, uma análise documental das ementas e dos planos de ensino foram realizados, bem como a aplicação de um questionário aos discentes, composto por dez perguntas. Foi possível concluir a adequação dos conteúdos lecionados, porém notou-se um déficit no processo de ensino aprendizagem dos acadêmicos (LIMA; GUEDERT, 2016). 
Ainda considerando a estruturação da disciplina e seu conteúdo, as percepções de discentes do curso de Medicina acerca do estudo anatômico foram avaliadas, buscando um melhor aproveitamento da mesma. O estudo foi feito pela aplicação de um questionário semi-estruturado para um total de 225 acadêmicos. Foi perceptível a sensação de insegurança dos alunos com relação ao seu conhecimento em Anatomia por insuficiência no aprendizado. Diante disso, observa-se a necessidade de aprimoramento do currículo do curso médico, com ênfase na disciplina de Anatomia, para que atenda à expectativa dos discentes (REIS et al., 2013).

Considerando ainda a percepção dos discentes no processo de ensino e aprendizagem da disciplina de Anatomia Humana, uma pesquisa foi conduzida para os cursos de Ciências Biológicas e Enfermagem de uma universidade do Centro-Oeste do Estado do Rio Grande do Sul, com 10 acadêmicos de cada curso. A coleta de dados se deu por meio de depoimentos em entrevistas semi-estruturadas com posterior análise. Concluiu-se, assim, que o ensino da Anatomia apresenta vários obstáculos que dificultam o aprendizado, incluindo: grande quantidade de estruturas anatômicas e nomenclaturas, necessidade de memorização e limitada associação com a prática profissional, disponibilidade de horário de estudo incompatível, dentre outros. Diante disso, mostra-se essencial que os professores tenham uma boa didática e ferramentas adicionais para aprimorar o ensino e a transmissão do conteúdo da melhor maneira possível, garantindo o melhor aproveitamento da mesma pelos acadêmicos (SALBEGO et al., 2015).

Diante dos fatos expostos, novas metodologias podem ser utilizadas para o ensino de Anatomia, destacando-se softwares, aplicativos e ferramentas tecnológicas capazes de auxiliar na compreensão do conteúdo. Neste sentido, realizou-se o desenvolvimento de um aplicativo para dispositivos móveis e a avaliação da percepção discente no intuito de utilizar o mesmo como ferramenta de apoio ao ensino e a aprendizagem em Anatomia Humana. Participaram 25 discentes do curso de Educação Física que construíram mapas mentais por meio de tablets e smartphones com conteúdos de Anatomia e um questionário de mapeamento da turma e uma avaliação reflexiva foi aplicada. Dessa forma, observou-se que o Mobile Learning pode ser uma estratégia de ensino interessante e também auxiliar o processo pedagógico acompanhando a evolução tecnológica e a sociedade moderna (COSTA et al., 2015).

Dentre as profissões que trabalham com o corpo humano, destaca-se o curso de Educação Física e a necessidade de inclusão deste conteúdo na sua ementa em ambas as modalidades, licenciatura e bacharelado. Sendo assim, a ementa da licenciatura em educação física da Universidade Federal de Goiás (UFG), Goiânia - Go, aponta os conhecimentos que serão transmitidos para os acadêmicos e que precisam ser adquiridos por eles no período em que estiver vigente a disciplina; Portanto, é colocado o estudo anátomo-funcional do Aparelho Locomotor, Sistema Nervoso e do Sistema Sensorial, dando atenção às questões musculares em seus diferentes contextos e a aplicação da anatomia no movimentar humano. Além disso, também é feito um estudo anátomo-funcional dos Sistemas Circulatório, Respiratório, Urogenital, Endócrino e Tegumentar, dando pontuações funcionais da aplicação da anatomia na Educação Física (FEFD/UFG - RESOLUÇÃO - CEPEC No 715, p. 10, 2005).

Analisando o fluxo curricular sugerido das disciplinas proposto para o curso de educação física licenciatura, a anatomia do movimento humano se encontra como uma disciplina que se desenvolve durante todo o primeiro ano de curso. Sendo assim a anatomia inicia os primeiros aprofundamentos acerca dessa área de conhecimento e dá abertura para os demais conteúdos que também estão vinculados a essa área, como a fisiologia e a biomecânica. A ementa do curso de educação física na modalidade bacharelado também traz as mesmas características da disciplina de anatomia humana presentes na 
licenciatura (FEFD/UFG - RESOLUÇÃO - CEPEC No 715, p. 17, 2005).

De acordo com as conclusões colocadas em seu artigo, Cardinot et al. (2014), pontuam que grande parte dos discentes concordaram que em seu curso e para um futuro próximo no mercado de trabalho à disciplina de anatomia humana é vista e colocada como importante. A partir disso, o objeto a ser estudado e trabalhado é relevante à disciplina de anatomia sendo essa área pertinente enquanto componente curricular do curso de educação física.

\section{METODOLOGIA}

O presente estudo consistiu de uma revisão descritiva da literatura, realizada por meio de pesquisa nas bases eletrônicas de dados da Biblioteca Virtual em Saúde (BVS), Lilacs, Medline, Scielo, Cochrane, Pepsic, Pubmed e Google Acadêmico. A seleção de artigos científicos foi realizada nos últimos 10 anos, contemplando a produção científica entre 2006 e 2016, utilizando as terminologias cadastradas nos Descritores em Ciências da Saúde (DECS), pela busca avançada e cruzamento dos termos em português e inglês, como: "anatomia" ou "anatomia humana" and "educação física" e "anatomy" ou "human anatomy" and "physical education". No total foram encontrados 1992 resultados de acordo com as buscas nas bases de dados.

A triagem dos artigos foi feita a partir da análise dos títulos e resumos, sendo incluídos os que continham os descritores mencionados e também os que abordavam a temática específica da importância da Anatomia para o curso de Educação Física, de acordo com os critérios de inclusão e exclusão estabelecidos. Em seguida, os artigos selecionados foram lidos na íntegra e analisados, com isso apenas seis foram utilizados para a presente análise e 1986 tiveram que ser excluídos.

Foram incluídos artigos completos, de livre acesso, em língua portuguesa e/ou inglesa, cujo tema incluía a importância do conhecimento de Anatomia Humana para acadêmicos do curso de Educação Física. Adicionalmente, foram excluídos artigos repetidos e que não foram encontrados nas bases de dados pesquisadas e aqueles cujo tema principal não envolviam a importância do conteúdo de Anatomia para o curso de Educação Física ou objetivo estavam voltados ao desenvolvimento de mídias, produtos digitais, recursos didáticos e/ou pedagógicos, aplicativos e demais avaliações das metodologias de ensinoaprendizagem da disciplina e suas ferramentas de trabalho como peças cadavéricas e/ou sintéticas.

Ainda foram desconsiderados estudos de estruturas anatômicas específicas, programas de exercícios físicos, patologias, condições clínicas e aqueles direcionados para outros cursos da área da saúde como fisioterapia, medicina, enfermagem, dentre outros. Artigos cujo destaque incluíam atividades de monitoria, projetos de extensão, disciplinas afins, análise do Projeto Pedagógico do Curso (PPC) e diretrizes curriculares, bem como em idiomas diversos, resumos, anais, dissertações, teses, livros e aqueles não disponíveis para acesso livre também foram excluídos da presente análise.

\section{RESULTADOS E DISCUSSÕES}

De acordo com a metodologia proposta, foram identificados inicialmente o quantitativo de estudos demonstrado na tabela 01 e apresentados no apêndice 01, considerando as diversas bases de dados pesquisadas. Ainda considerando a inclusão de pesquisas específicas com relação à temática da importância da Anatomia para a Educação Física, observou-se um número limitado de estudos que 
atendem aos critérios de inclusão e exclusão estabelecidos. Do total de estudos encontrados, apenas seis foram utilizados para a presente análise, visto que a maioria não atendia aos critérios de inclusão e exclusão pré-estabelecidos.

Tabela 1 - Representação do número de artigos encontrados nas diversas bases de dados de acordo com o Decs.

\begin{tabular}{|c|c|c|}
\hline DeCS & Base de Dados & Número de Artigos \\
\hline "Educação Física" AND & BVS & 172 \\
\hline "Anatomia" ou "Physical & Lilacs & 3 \\
\hline Education" AND "Anatomy" & Medline & 143 \\
\cline { 2 - 3 } & Scielo & 1 \\
\hline "Educação Física" AND & Cochrane \\
\hline "Anatomia & Pepsic & 0 \\
\hline Humana" ou "Physical & Pubmed & 541 \\
\hline Education" AND "Human & Google Acadêmico & 1120 \\
\hline Anatomy" & & \\
\hline
\end{tabular}

$\mathrm{Na}$ análise dos artigos selecionados, o nível de conhecimento dos profissionais que atuam na área de musculação considerando o saber da Anatomia Humana foi analisado por meio de uma pesquisa com 70 profissionais da cidade de Goiânia-GO e região do Vale do Aço-MG, incluindo também o nível de satisfação desses profissionais com relação ao conteúdo ministrado na graduação. A coleta de dados foi realizada por meio da utilização de um questionário composto por 27 questões, sendo 07 delas subjetivas capazes de avaliar a satisfação e o aprendizado em relação ao conhecimento na disciplina durante a graduação, e 20 questões objetivas, com aplicação direta na musculação para verificar o nível de conhecimento dos entrevistados em relação ao conteúdo proposto. Diante disso, pôde-se observar a necessidade dos profissionais de um maior aprimoramento teórico-prático da Anatomia Humana e de capacitação intelectual visando garantir um melhor desenvolvimento do seu trabalho profissional. Além disso, foi ressaltada a pouca experiência profissional dos envolvidos e a necessidade de mais fiscalizações nas academias. Assim, as universidades e os acadêmicos devem buscar um novo olhar e se preocupar com o trato dessa disciplina, para que os futuros atuantes possam ter uma boa correlação do conteúdo abordado com o seu trabalho (GUIMARÃES et al., 2014).

Neste sentido, discentes dos cursos de Educação Física e Fisioterapia avaliaram a importância atribuída para a disciplina de Anatomia Humana e para as atividades de monitoria em relação ao seu curso de graduação da Abeu Centro Universitário de Belford Roxo/RJ. A pesquisa foi realizada por meio da aplicação de um questionário a 63 acadêmicos, sendo 39 do curso de Educação Física e 24 de 
Fisioterapia. Os mesmos consideraram importante a disciplina de anatomia humana para o seu respectivo curso e para o seu futuro profissional. No entanto, a frequência dos estudantes nas monitorias foi baixa apesar de reconhecerem a necessidade do estudo das estruturas anatômicas (CARDINOT et al., 2014).

Apesar da constatação da relevância do conhecimento em Anatomia, nota-se uma evasão e exclusão de discentes na disciplina dos cursos de Educação Física, nas modalidades Licenciatura e Bacharelado, do Centro Universitário Metodista do IPA. O estudo levanta questionamentos sobre as possíveis causas e os métodos de ensino utilizados pelo docente, comparando o método tradicional com ferramentas mais inovadoras. Neste sentido, a presente pesquisa avaliou 32 estudantes no ano de 2011 por meio da utilização de um questionário aplicado no início da disciplina e outro ao final da mesma. Dessa forma, observou-se que um método diferenciado pode gerar uma compreensão considerada satisfatória e minimiza as exclusões e abandonos por parte dos discentes. Assim, a utilização de um método de ensino diferenciado e mais atrativo pelo docente, com a utilização de cadáveres e livros, ajudou os alunos a terem uma maior aceitação e compreensão da disciplina (PIAZZA; CHASSOT, 2011).

Além disso, os fatores que influenciam a taxa de aprovação na disciplina de Anatomia Humana foram estudados visando obter uma relação entre o resultado do Vestibular/Enem, os hábitos de estudo e o desempenho na disciplina pelos discentes dos cursos de Educação Física, Ciências Biológicas e Nutrição, do Instituto Federal do Sudeste de Minas Gerais. A pesquisa contou com a inclusão de cerca de 129 alunos que tenham cursado a disciplina de Anatomia Humana, entre os anos de 2011 a 2013, independentes de terem ou não sido aprovados na mesma. Uma entrevista estruturada por perguntas com pontuações a indicadores sociodemográficos, hábitos de estudo e escolha profissional foi executada. Com relação ao vestibular, a nota obtida pelo aluno entrevistado foi concedida mediante solicitação ao reitor, enquanto a nota do Enem foi informada pelo estudante de acordo com a publicação no site referente ao mesmo. A análise referente às notas do Vestibular/Enem definiu com maior índice aos alunos aprovados na disciplina de Anatomia Humana. No entanto, não foi evidenciada diferenciação com relação às horas de estudo e o curso escolhido. Diante disso, o presente trabalho pode fornecer informações referentes aos ingressantes e seu êxito ao longo da vida acadêmica, incentivando a busca pela formação constante do aluno e o estabelecimento de uma educação de qualidade (SILVA-e-OLIVEIRA; FURTADO, 2015).

Adicionalmente, o processo de ensino da disciplina de Anatomia Humana para a formação do profissional de educação física foi estudado por meio de uma abordagem exploratória, interpretativa e nãoexperimental, no qual os dados foram coletados pela observação e representações verbais. A amostra foi constituída por nove professores de Anatomia Humana que lecionam para o curso de Educação Física, em sete universidades particulares na cidade de São Paulo e região metropolitana. Por meio da observação de aulas teóricas e práticas objetivou-se recolher informações para entender melhor o processo de ensino sobre os atributos de uma aprendizagem significativa. Dessa forma, as aulas observadas geraram um relatório que sintetiza essas questões, bem como as descrições do que foi observado em relação aos procedimentos didático-pedagógicos adotados pelos docentes. Assim, foi possível notar que a contextualização da disciplina de anatomia humana e de suas características acadêmicas com a atividade executada pelos profissionais de educação física são necessárias, para que a aprendizagem significativa tenha seu lugar. O planejamento das aulas e a associação do conhecimento às necessidades acadêmicas e profissionais da área são essenciais, uma vez que dificuldades são observadas na assimilação do conteúdo e na identificação do significado e utilidade do que está sendo aprendido (COSTA; GAMA; SILVA, 2010). 
Ainda considerando as informações mencionadas, o método de ensino da Anatomia Humana também tem sido alvo de estudos. Uma pesquisa descritivo-exploratória foi realizada em seis instituições de ensino superior que possuem o curso de Educação Física, nas modalidades Licenciatura e Bacharelado, no intuito de estabelecer um método de ensino da Anatomia Humana, na cidade de Porto Alegre - RS. Um docente de cada instituição que ministra a presente disciplina e com experiência prévia, participaram do estudo. A coleta de dados foi realizada por meio de uma entrevista semi-estruturada, contendo dados que se referem à grade curricular do curso e da ementa da disciplina. Com isso, pôde-se concluir que as instituições contam com profissionais bastante qualificados em ministrar seu conteúdo, com variações entre o método sistêmico-topográfico e o método sistêmico. No entanto, a disciplina necessita de maior carga horária e visibilidade na grade curricular, pois a limitação de tempo restringe o estudo de conteúdos primordiais que não são abordados de forma aprofundada (PIAZZA; REPPOLD FILHO, 2011).

Diante dos estudos apresentados, pode-se notar a importância do conhecimento de estruturas anatômicas do corpo humano para estudantes e profissionais da Educação Física. Entretanto, metodologias de ensinoaprendizagem associadas à busca intelectual constante dos envolvidos devem ser estimuladas. $\mathrm{Na}$ presente revisão de literatura, limitados trabalhos foram encontrados especificamente para a área de Educação Física, necessitando de pesquisas adicionais capazes de responder questões ligadas ao estudo do corpo humano e aquelas relacionadas ao melhor desempenho didático e pedagógico dos estudantes. Avaliações pedagógicas, do PPC, ementas, metodologias de ensino, dentre outras, foram encontradas, no entanto, não contemplavam particularmente a importância da área de Anatomia para o curso e formação do profissional.

O mesmo ao trabalhar com o movimento e estruturas corporais visa a constante busca e manutenção de condições físicas adequadas e a manutenção e aperfeiçoamento da saúde do indivíduo, garantindo uma maior disposição para as atividades diárias e consequente melhora da qualidade de vida dos praticantes. A partir de um conhecimento aprofundado e posteriormente adquirido, o profissional de educação física estará mais assegurado para com a sua profissão, pois poderá na maioria das vezes, a partir de uma ciência internalizada por meio do estudo, evitar que haja lesões e/ou sequelas por parte de seus alunos através de uma prática inadequada ou execução equivocada de movimentos.

Em alguns momentos no decorrer do trabalho foi pontuada a incompreensão da disciplina de anatomia humana. Portanto, seria interessante e viável se houvessem algumas reformulações curriculares para que essa disciplina possa gerar um rendimento melhor e mais apropriado para a área de Educação Física. Contudo, esse problema não vislumbra somente isso em razão de que a falta de interesse dos estudantes em querer buscar esse conhecimento que futuramente será muito importante em sua vida profissional também se encontra de lado. Então, em parte, esses estudantes precisam se motivar mais e buscar a chave desse conhecimento.

\section{CONCLUSÃO}

De acordo com o presente trabalho, pode-se concluir a importância da aquisição e manutenção do conhecimento na área de anatomia humana para a formação do graduado em educação física e sua aplicabilidade na vida e no cotidiano do profissional.

No entanto, sua real importância encontra-se subestimada, necessitando de pesquisas adicionais capazes de elucidar seu papel fundamental na formação intelectual, técnica e prática dos graduados. Destaca-se 
que mais trabalhos sejam publicados a respeito da importância da anatomia humana para a educação física, pois poucos tratam dessa relação e relevância. Então, um trabalho mais abrangente seria o ideal para tentar unir as informações que se possuem do passado até nos dias atuais formando assim um arcabouço teórico mais completo.

Conclui-se idem baseado no que foi fundamentado no tópico resultados e discussões o referente trabalho utilizou somente do quantitativo de estudos indicados em virtude dos demais não atenderem aos objetivos expostos do trabalho e/ou focarem em áreas diversas ou análises de tópicos intrínsecos a metodologia. A partir disso se vê que ainda é necessário fazer um trabalho mais abrangente como dito no parágrafo acima e esse possa ser tornar fonte de estudo para outras pessoas terem auxílio em seus futuros trabalhos e que a partir disso também realizem novas pesquisas e estudos sobre o tema.

\section{REFERÊNCIAS}

CARDINOT, T. M. et al. Importância da disciplina de Anatomia Humana para os discentes de educação física e fisioterapia da ABEU centro universitário de Belford Roxo/RJ. Coleção Pesquisa em Educação Física, Várzea Paulista/SP, v. 13, n. 1, p.95-102, 2014.

COLETIVO DE AUTORES. Metodologia do ensino de Educação Física. Ed. Cortez, 1992.

DAMASCENO, S. A. N; CÓRIA-SABINI, M. A. Ensinar e aprender: saberes e práticas de professores de Anatomia Humana. Relato de Pesquisa. Rev. Psicopedagogia 2003; 20(63): 243-54.

CORRÊA, A. A. et al. Michelangelo: Uma contribuição à anatomia. Revista Cientifica Eletrônica de Medicina Veterinária - ISSN: 1679-7353. Ano VI - Número 11 - Julho de 2008 - Periódicos Semestral.

COSTA, A. P; GAMA, E. F; SILVA, S. A. P .S. The formation of the physical education professional: teaching the discipline of human anatomy - tradução: A formação do profissional de educação física: o ensino da disciplina de anatomia humana. J. Morphol. Sci., 2010, vol. 27, no. 2, p. 105-111.

COSTA, G. B. F; COSTA, G. B. F; LINS, C. C. S. A. O Cadáver no Ensino da Anatomia Humana: uma Visão Metodológica e Bioética. Revista Brasileira de Educação Médica, 2012.

COSTA, R. D. A. et al. Percepções de acadêmicos sobre o desenvolvimento de um aplicativo para dispositivos móveis como ferramenta de apoio ao ensino e a aprendizagem em Anatomia Humana. V. $4 \mathrm{~N}^{\mathrm{o}} 1$ Novembro, 2015.

EDUCAÇÃO FÍSICA: seu manual de saúde. São Paulo: DCL, 2012.

FEFD/UFG. Resolução - CEPEC $\mathbf{n}^{\mathbf{0}}$ 715. Disponível em: < https://www.fefd.ufg.br/up/73/o/Resolucao_CEPEC_2005_0715.pdf> Acesso em: 06 de Julho de 2016.

GUIMARÃES, N. N. et al. Análise comparativa dos profissionais de musculação em relação ao seu conhecimento sobre Anatomia Humana, na cidade de Goiânia - GO e Região do Vale do Aço MG, no ano de 2012. Revista Eletrônica de Educação da Faculdade Araguaia, 5: 150-161, 2014. 
LIMA, P; GUEDERT, D. G. Estudo da Anatomia Humana no curso de graduação em Fisioterapia na Universidade Regional de Blumenau: uma visão documental e discente. Atos de Pesquisa em Educação - ISSN 1809-0354. Blumenau, v. 11, n.1, p.271-292, jan./abr. 2016. DOI: http://dx.doi.org/10.7867/1809-0354.2016v11n1p271-292.

LIRA, W; ALVES, K. A anatomia do corpo humano através da arte. XIII Encontro Nacional de Educação em Ciências, 2009.

MENESTRINA, E. Educação Física e Saúde. 3. ed. rev. ampl. - Ijuí: Ed. Unijuí, 2005.—112 p.

PAULSEN, F; WASCHKE, J. Sobotta: Atlas de Anatomia Humana: Anatomia Geral e Sistema Muscular. Traduzido por Marcelo Sampaio Narciso; sob a supervisão de Adilson Dias Salles. - Rio de Janeiro: Guanabara Koogan, 2012.

PIAZZA, B. L; CHASSOT, A. I. Anatomia Humana, uma disciplina que causa evasão e exclusão: quando a hipótese principal não se confirma. Ciência em Movimento | Ano XIV | $\mathrm{N}^{\circ} 28$ | $2011 / 2$.

PIAZZA, B. L; REPPOLD FILHO, A. R. O ensino de anatomia humana nos cursos de Educação Física da região metropolitana de Porto Alegre. Ciência em Movimento | Ano XIII | No 26 |2011/2.

REIS, C. et al. Avaliação da Percepção de Discentes do Curso Médico acerca do Estudo Anatômico. Revista Brasileira de Educação Médica, 2013.

SAlBego, C. et al. Percepções Acadêmicas sobre o Ensino e a Aprendizagem em Anatomia Humana. Revista Brasileira de Educação Médica, 2015.

SILVA-e-OLIVEIRA, J. FURTADO, F. Quais Fatores Influenciam a Taxa de Aprovação na Disciplina de Anatomia Humana? Revista Brasileira de Educação Médica, 2015.

TARDIF, M. Saberes docentes e formação profissional. Petrópolis, R.J.: Editora Vozes, 2002. Instrumento: R. Est. Pesq. Educ. Juiz de Fora, v. 10, p. 143-145, jan./dez. 2008.

APÊNDICE 1 - Gráfico representativo do número de artigos encontrados nas diversas bases de dados de acordo com o Decs 


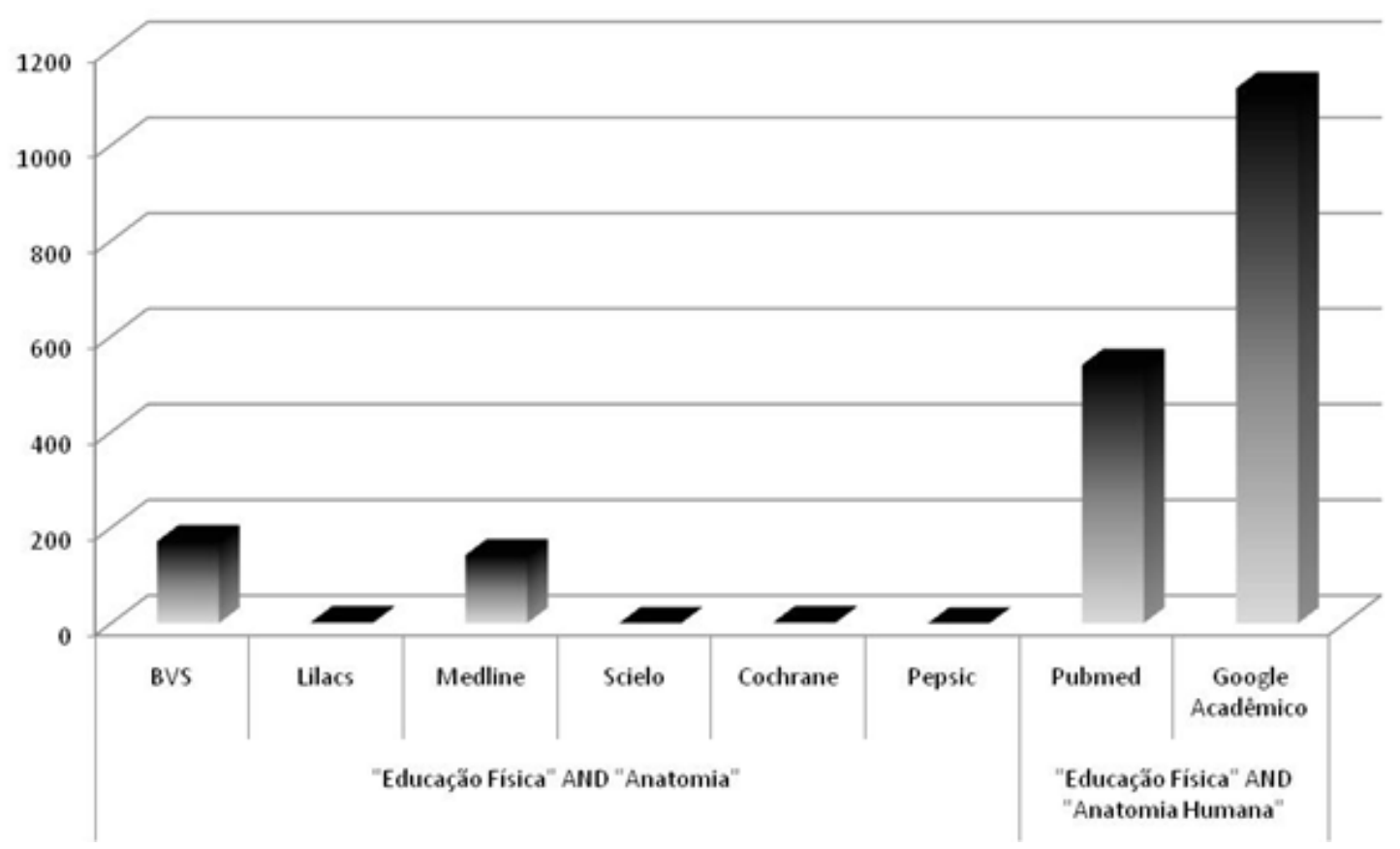

m Número de Artigos

Gráfico 1 - Representação do número de artigos encontrados nas diversas bases de dados de acordo com o Decs.

${ }^{[1]}$ Graduação em Licenciatura em Educação Física pela Universidade Federal de Goiás (2013 - 2016) em processo de finalização

[2] Graduada em Odontologia pela Universidade Federal de Uberlândia. Mestre e Doutora em Biologia Buco-Dental com concentração em Anatomia pela Faculdade de Odontologia de Piracicaba FOP / UNICAMP. Especialista em Anatomia Humana. Atualmente atuando como docente do Curso de Medicina, área de Anatomia Humana, na Universidade Federal de Goiás - UFG/Regional Jataí.

${ }^{\text {[3] }}$ Possui Graduação (2003) e Mestrado (2008) em Odontologia pela Universidade Federal de Uberlândia e Doutorado em Anatomia Humana pela FOP / UNICAMP. Tem experiência na área de Odontologia e Anatomia Humana, com ênfase em pesquisa musculoesquelética, estudo de Disfunções da ATM, eletromiografia e ultrassonografia muscular. Ampla experiência em de cargos administrativos, coordenação e membro de equipes de avaliadores em extensão universitária.

${ }^{[4]}$ Turismóloga, Doutoranda em Geografia, professora da Universidade Federal do Piaui.

${ }^{[5]}$ Biólogo. Doutor em Medicina/Doenças Tropicais. Docente e Pesquisador na Universidade Federal do Pará - UFPA. Pesquisador no Laboratório de Toxicologia Humana e Ambiental e no Laboratório de Estresse Oxidativo do Núcleo de Medicina Tropical da UFPA (NMT-UFPA).

[6] Teóloga, Doutora em Psicanálise Clínica. Atua há 15 anos com Metodologia Científica ( Método de Pesquisa) na Orientação de Produção Científica de Mestrandos e Doutorandos. Especialista em Pesquisas de Mercado e Pesquisas voltadas a área da Saúde. 
Revista Científica Multidisciplinar Núcleo do Conhecimento - RC: 12706 - ISSN: 2448-0959

https://www.nucleodoconhecimento.com.br/saude/anatomia-humana

\section{PUBLIQUE SEU ARTIGO CIENTÍFICO EM:}

https://www.nucleodoconhecimento.com.br/enviar-artigo-cientifico-para-submissao 